\title{
Cyclic peroxides as key intermediates in the degradation of cellulosic key chromophores by alkaline hydrogen peroxide: first direct proof by ${ }^{17} \mathrm{O}$ NMR
}

\author{
Markus Bacher - Takashi Hosoya $\cdot$ Nele Sophie Zwirchmayr $\cdot$ Satoshi Nomura \\ Lars Gille - Thomas Dietz - Tomoki Erata - Antje Potthast - Tapani Vuorinen • \\ Thomas Rosenau $(\mathbb{D}$
}

Received: 15 February 2018/ Accepted: 2 April 2018/Published online: 30 April 2018

(C) The Author(s) 2018

\begin{abstract}
Dihydroxy-[1,4]-benzoquinone (DHBQ) and 5,8-dihydroxy-[1,4]-naphthoquinone (DHNQ) are two key chromophores which are almost ubiquitous in cellulosic materials. Their fate under conditions of alkaline peroxide bleaching (P stage) has been established previously, but the intermediacy of cyclic peroxides, which so far had only been postulated, remained an open issue. By means of ${ }^{17} \mathrm{O}$ NMR spectroscopy, additionally supported by other NMR
\end{abstract}

M. Bacher - N. S. Zwirchmayr · S. Nomura ·

A. Potthast · T. Rosenau ( $\square)$

Division of Chemistry of Renewable Resources,

Department of Chemistry, University of Natural

Resources and Life Sciences, Muthgasse 18, 1190 Vienna,

Austria

e-mail: thomas.rosenau@boku.ac.at

T. Hosoya

Graduate School of Life and Environmental Sciences,

Kyoto Prefectural University, Shimogamo-hangi-cho

11-5, Sakyo-ku, Kyoto-shi, Kyoto, Japan

S. Nomura - T. Erata

Graduate School of Engineering, Hokkaido University,

Sapporo, Japan

L. Gille

Department of Biomedical Sciences, University of

Veterinary Medicine Vienna, Veterinärplatz 1,

1210 Vienna, Austria techniques, it was demonstrated that both DHBQ and DHNQ form cyclic peroxides as primary intermediates in the reaction with hydrogen peroxide under alkaline conditions. These intermediates are subsequently further degraded to products already known. The experimental confirmation of the cyclic peroxides is an important step in the understanding of reaction mechanisms in pulp bleaching chemistry.

\author{
T. Dietz \\ Evonik-Degussa, Rodenbacher Chaussee 4, \\ 63457 Hanau-Wolfgang, Germany \\ T. Vuorinen \\ Department of Bioproducts and Biosystems, Aalto \\ University, Vuorimiehentie 1, 02150 Espoo, Finland \\ T. Rosenau \\ Johan Gadolin Process Chemistry Centre, Åbo Akademi \\ University, Porthansgatan 3, 20500 Åbo/Turku, Finland
}




\section{Graphical Abstract}

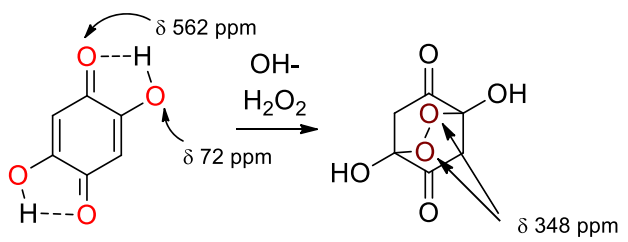

DHBQ

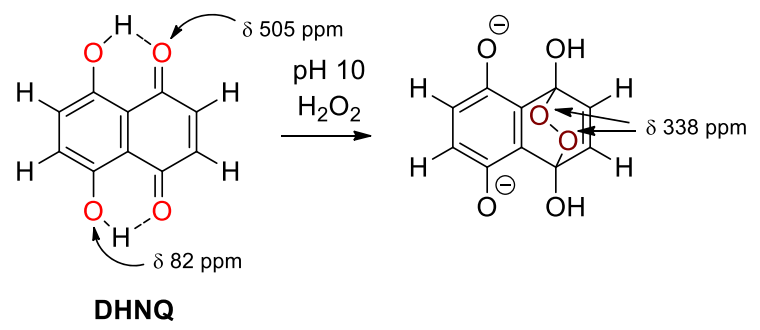

Keywords Cellulose - Chromophores ·

Benzoquinone $\cdot$ Naphthoquinone $\cdot$ Cyclic peroxides . $\mathrm{P}$ stage $\cdot$ Pulp bleaching $\cdot{ }^{17} \mathrm{O}$ NMR

\section{Introduction}

Three compounds have been established as key chromophores in cellulosic matrices: 2,5-dihydroxy1,4-benzoquinone (1), 5,8-dihydroxy-naphthoquinone (2), and 2,5-dihydroxyacetophenone (Korntner et al. 2015). Because of their exceptionally strong resonance stabilization they are the main survivors of bleaching attempts, and due to their exceptional thermodynamic stability they are readily re-formed from low-molecular weight degradation products upon aging and brightness reversion. It is their ubiquity in cellulosic materials that makes them prime targets of mechanistic studies, which aim both at a better understanding of their bleaching chemistry and at high efficiency of their removal or destruction-in terms of both reactivity and costs.

The degradation of the key chromophores under conditions of industrial peroxide bleaching ("P stage"), i.e. by treatment with alkaline hydrogen peroxide, has been studied in detail. The kinetics as well as the reaction mechanism, stable intermediates and final degradation products, mostly $\mathrm{C}_{1}$ to $\mathrm{C}_{4}$ acids and hydroxyacids and carbon dioxide, have been established (Hosoya and Rosenau 2013a; Zwirchmayr et al. 2017). One question that remained open, however, was the intermediacy of cyclic peroxides $\mathbf{1 b}$ and $\mathbf{2 b}$ (Schemes 1,2). The occurrence of these intermediates has been postulated from in-depth computational treatments of the reaction pathways (Hosoya and Rosenau 2013a; Zwirchmayr et al. 2017), and NMR experiments provided some faint indication of their existence, but solid proof was still missing. In particular ${ }^{1} \mathrm{H}$ and ${ }^{13} \mathrm{C}$ NMR spectroscopy was inconclusive insofar as resonances of putative intermediates were in agreement with the cyclic peroxides' structure, but would fit also to other structurally similar compounds.

The task how to prove the existence of such transient cyclic peroxide intermediates along the degradation pathway from the chromophores to the final low-molecular weight products was not trivial. Complicating was evidently the fact that the intermediates - as per definition — were not stable, so that they could not be isolated or determined by chromatographic techniques. In addition, they were present in a rather complex mixture, and their high symmetry made conventional ${ }^{1} \mathrm{H}$ and ${ }^{13} \mathrm{C}$ NMR techniques less meaningful due to low numbers of characteristic resonances (note, for instance, that the dianion of DHBQ (1a) produces a singlet in ${ }^{1} \mathrm{H}$ NMR and two singlets in ${ }^{13} \mathrm{C}$ NMR).

We came up with ${ }^{17}$ O NMR (Berger et al. 1997; Boykin 1990; Klemperer 1978; Chandrasekaran et al. 1984; Gerothanassis 2010a, b) as a means to tackle this problem. This variant of non-metal NMR is still relatively little used, which is mainly due to the fact that ${ }^{17} \mathrm{O}$ is rather rare $(0.037 \%)$ and ${ }^{17} \mathrm{O}$-labelled compounds are consequently rather uncommon and very expensive. In addition, ${ }^{17} \mathrm{O}$ is a spin $5 / 2$ nucleus with moderate quadrupole moment, which produces notoriously broad resonances, and low receptivity of 0.06 relative to ${ }^{13} \mathrm{C}$. This, however, is to a certain extent counterbalanced by the fact that the chemical shift range for ${ }^{17} \mathrm{O}$ is quite extensive and covers more than $800 \mathrm{ppm}$ for organic compounds $(1800 \mathrm{ppm}$ in total), compared to about $15 \mathrm{ppm}$ for ${ }^{1} \mathrm{H}$ and approx. $230 \mathrm{ppm}$ for ${ }^{13} \mathrm{C} .{ }^{17} \mathrm{O}$ NMR of non-enriched compounds (natural isotopic abundance) is possible for neat liquids or highly concentrated solutions (Fig. 1), but analysis of any component below $10 \mathrm{wt} \%$-or even as low as "usual" NMR concentrationsrequires isotopic labelling. 

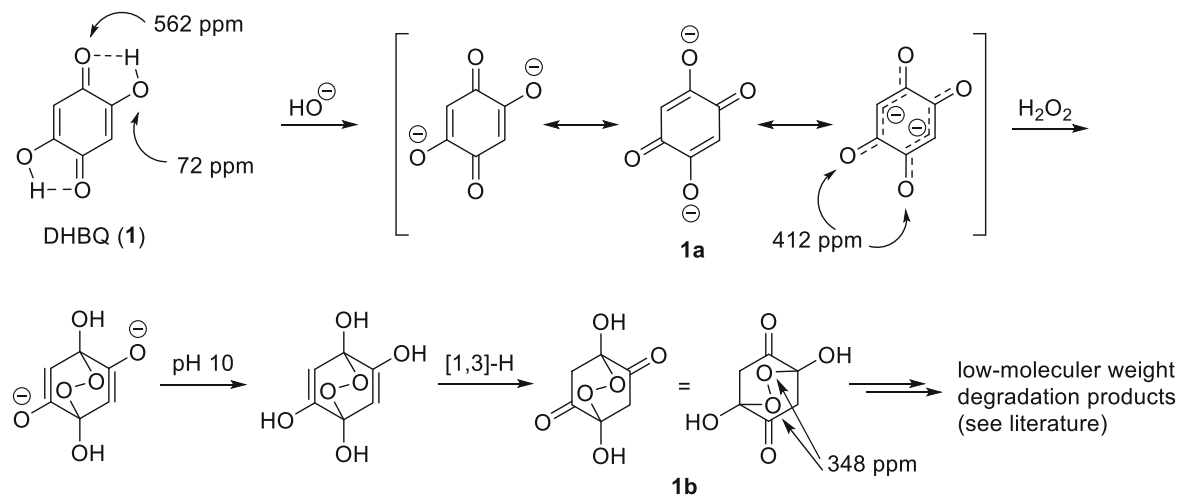

Scheme 1 DHBQ 1, its dianion 1a and its primary intermediate 1b, formed upon reaction with $\mathrm{H}_{2} \mathrm{O}_{2}$ under alkaline conditions. For ppm data $\left({ }^{17} \mathrm{O}\right.$ NMR) see text. With the reaction proceeding, low molecular weight degradation products (mainly carbonate, acetate and malonate) are formed (Hosoya and Rosenau 2013a), with no other intermediate along the path that is stable enough for ${ }^{17} \mathrm{O}$ NMR observation

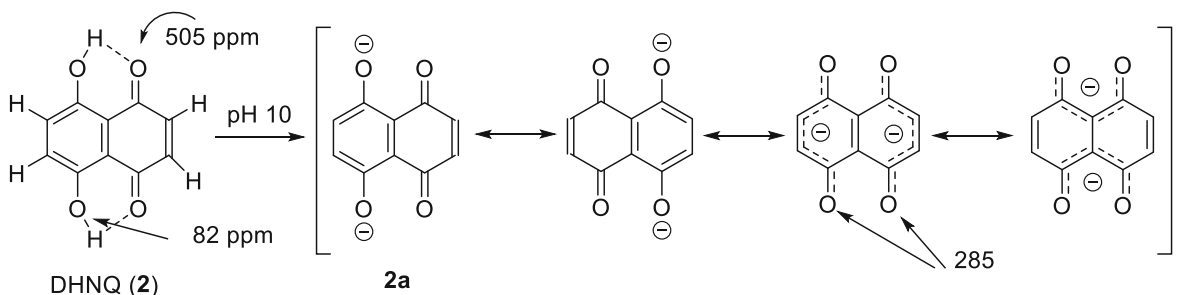

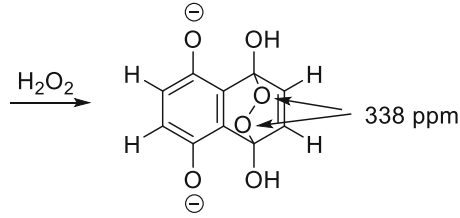

2b

Scheme 2 DHNQ 2, its dianion 2a and its primary intermediate $\mathbf{2 b}$, formed upon reaction with $\mathrm{H}_{2} \mathrm{O}_{2}$ under alkaline conditions. As the final products, low molecular weight degradation products (mainly carbonate, acetate, and maleate) are generated

\section{Results and discussion}

In concentrated organic solution (DMSO), both DHBQ (1) and DHNQ (2) exhibit two resonances in ${ }^{17} \mathrm{O}$ NMR, corresponding to the two equivalent quinone oxygens and the two equivalent hydroxyl oxygens. In neutral aqueous solution, DHBQ (1) is already fully dissociated and present as its dianion $\mathbf{1 a}$. Its two hydroxyl groups are rather acidic with $\mathrm{pKa}$ values of 2.7 and 5.2, respectively. The pKa values of DHNQ (2), 7.8 and 9.2, indicate that formation of the corresponding dianion $\mathbf{2 a}$ requires alkaline media. At a reaction $\mathrm{pH}$ of 10 , chosen to set the same conditions as in previous experiments (Hosoya and Rosenau 2013a;
(Zwirchmayr et al. 2017). 1,4,5,8-Naphalenetetraone occurring later as intermediate in the degradation sequence (Zwirchmayr et al. 2017) exhibits a ${ }^{17} \mathrm{O}$ resonance at $634 \mathrm{ppm}$ (formula not shown)

Zwirchmayr et al. 2017), both $\mathbf{1}$ and $\mathbf{2}$ are fully deprotonated and present as their dianions 1a and $\mathbf{2 a}$. This brings about drastic changes in the NMR spectra. While 1 exhibits three ${ }^{13} \mathrm{C}$ resonances (for the quinoid, the methine and the hydroxyl-bearing carbon), the keto and hydroxylated carbons are rendered magnetically equivalent in dianion 1a, which consequently exhibits only two resonances (methine and $\mathrm{C}-\mathrm{O}$ ). This structural change upon deprotonation is also reflected in ${ }^{17} \mathrm{O}$ NMR: the two resonances (keto-oxygen and hydroxyl-oxygen) in neutral DHBQ become one resonance in the dianion 1a, in which all four oxygens are magnetically equivalent (Scheme 1). This is another nice support for the resonance structure in 


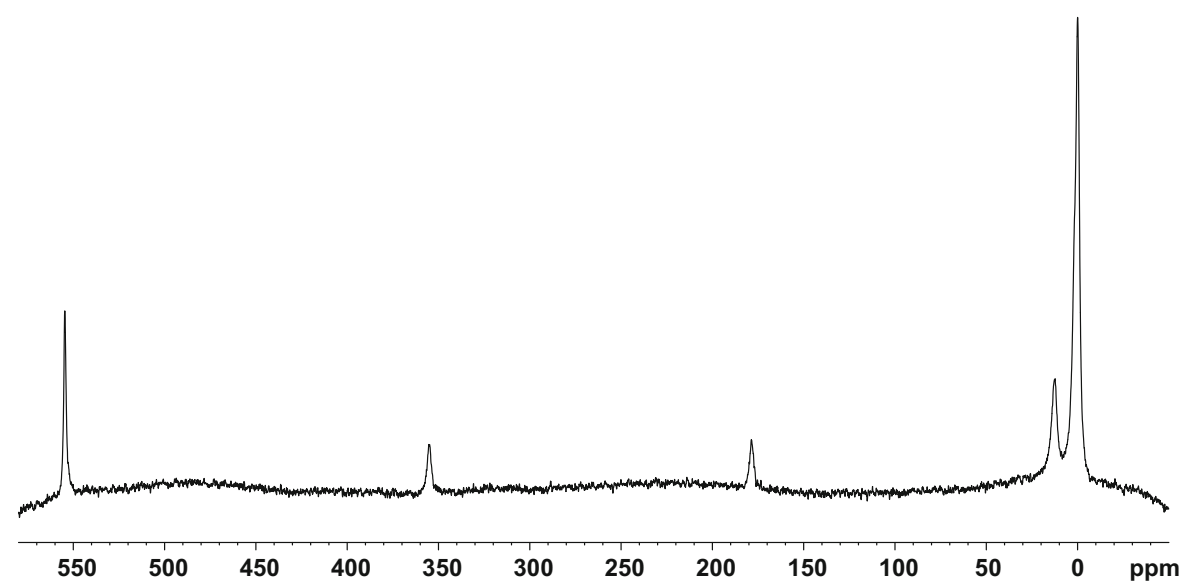

Fig. $1{ }^{17} \mathrm{O}$ NMR spectrum of an equimolar mixture of water $(0.00 \mathrm{ppm})$, ethanol $(12.3 \mathrm{ppm})$, ethyl acetate (178.6 ppm for $-\mathrm{O}-$ and $355.3 \mathrm{ppm}$ for $=\mathrm{O})$, and acetone $(554.6 \mathrm{ppm})$ at natural isotopic abundance, i.e. $0.037 \%$ of total $\mathrm{O}$

1a with its fully delocalized charges and double bonds, which is the main reason for the recalcitrance of the compound towards common bleaching agents that act on (localized) double bonds.

In neutral aqueous solution, DHNQ (2) produces two singlet peaks in ${ }^{1} \mathrm{H}$ NMR spectra, coming from the pair of equivalent protons of the "quinoid half" and the "aromatic half", those two parts being also clearly seen in the ${ }^{13} \mathrm{C}$ NMR spectra. ${ }^{17} \mathrm{O}$ NMR gives two resonances, one for the quinoid oxygen atoms and the other for the phenolic hydroxyl oxygens. The changes upon deprotonation to corresponding dianion $\mathbf{2 a}$ are, once more, drastic. While neutral 2 has only one mirror plane through the centers of the $\mathrm{C} 2-\mathrm{C} 3$ and C6C7 bonds, dianion $\mathbf{2 a}$ has an additional mirror plane along the annulation bond $(\mathrm{C} 4 \mathrm{a}-\mathrm{C} 8 \mathrm{a})$; in other words, the "quinoid side" and the "aromatic side" become indistinguishable (Becker 1999). ${ }^{1} \mathrm{H}$ NMR of 2a exhibits one singlet, ${ }^{13} \mathrm{C}$ NMR three singlets (annulated carbons, methine carbons and oxygenated carbons), and ${ }^{17} \mathrm{O} N M R$ one resonance. All four oxygens become magnetically equivalent in $\mathbf{2 a}$ (Scheme 2). The ${ }^{17} \mathrm{O}$ NMR data of $\mathbf{1}$ and $\mathbf{2}$ in acidic organic solution and 1a and 2a in alkaline aqueous solution were acquired with compounds of $2 \%{ }^{17} \mathrm{O}$ isotopic enrichment, of which the syntheses will be reported elsewhere. For these solutions acquisition times of about $1 \mathrm{~h}$ were sufficient, comparable to spectra of neat solvents (e.g. $\mathrm{D}_{2} \mathrm{O}$, acetone, ethanol) at natural isotopic abundance, i.e. without isotopic enrichment (Fig. 1).
In the case of experiments on possible oxygenated intermediates, such long measurement times are evidently unfeasible because the intermediates have a lifetime of only several minutes at room temperature, as known from previous kinetic studies (Hosoya and Rosenau 2013a; Zwirchmayr et al. 2017). Therefore, isotopic enrichment had to be employed and, in addition, lower temperatures $\left(0^{\circ} \mathrm{C}\right)$ to decrease the reaction rate. A $30 \mathrm{wt} \%$ aqueous solution of $\mathrm{H}_{2} \mathrm{O}_{2}$ with an isotopic labelling degree of $5 \%{ }^{17} \mathrm{O}$ was used. The ${ }^{17} \mathrm{O}$-enrichment in the hydrogen peroxide was thus approx. 135 times higher than natural isotopic abundance, which shortened the acquisition times in ${ }^{17} \mathrm{O}$ NMR to about $10 \mathrm{~min}$. No resonances except those from the labelled $\mathrm{H}_{2} \mathrm{O}_{2}$-oxygens are "seen" in these spectra, because signals of oxygens with natural isotopic abundance do not appear. In our experiments, a $1 \mathrm{M}$ alkaline solution ( $\mathrm{pH}$ 10) of either DHBQ (1) or DHNQ (2) was used, and the isotopically enriched $\mathrm{H}_{2} \mathrm{O}_{2}$ was added to a molar ratio between chromophore and $\mathrm{H}_{2} \mathrm{O}_{2}$ of $1: 3$. Spectra were accumulated at $10 \mathrm{~min}$ intervals over $1 \mathrm{~h}$ and after $2 \mathrm{~h}$. After that time all signals of starting oxidant and primary intermediates had disappeared and the degradation reaction had completed. This was also reflected in the oxygen resonances that had dissipated into many small signals in the carboxylate (deprotonated acids), hydroxyl and carbonate region, corresponding to the final degradation products that had been previously identified and reported (Hosoya and Rosenau 2013a, b; Zwirchmayr et al. 2017). 
The neat $\mathrm{H}_{2} \mathrm{O}_{2}$ starting solution gave the typical ${ }^{17} \mathrm{O}$ signal at $180 \mathrm{ppm}$. Rewardingly, the ${ }^{17} \mathrm{O}$ NMR spectra of the reaction mixture recorded in the initial two $10 \mathrm{~min}$ intervals were dominated (apart from the signal of excess $\mathrm{H}_{2} \mathrm{O}_{2}$ ) by a singlet around $340 \mathrm{ppm}$ (348 ppm in the case of benzoquinone $\mathbf{1}$ as the starting compound, and $338 \mathrm{ppm}$ in the case of naphthoquinone 2). This is highly indicative of cyclic, symmetric peroxides with two magnetically equivalent oxygens. The hydrogen peroxides thus introduced an intramolecular O-O bridge into both chromophoric systems by double nucleophilic, entropically driven attack, forming the cyclic peroxides $\mathbf{1 b}$ and $\mathbf{2 b}$, respectively, as the primary reaction intermediate along the extensive degradation pathways (Fig. 2). The possibility of the intermediate being a hydroperoxide R-OOH can be eliminated: there would be two resonances for the two inequivalent oxygens, with the $\mathrm{OH}$ oxygen typically appearing around $200 \mathrm{ppm}$, the $\mathrm{R}-\mathrm{O}$ oxygen between 300 and $380 \mathrm{ppm}$. A cleavage of the inter-oxygen bond in $\mathrm{H}_{2} \mathrm{O}_{2}$ can also be ruled out because possible product alcohols (approx. -50 to $80 \mathrm{ppm}$ ), ethers ( -30 to $50 \mathrm{ppm}$ ) or keto compounds ( -530 to $630 \mathrm{ppm}$ ) would resonate in completely different shift regions, and no signals were present there.

With the knowledge of the cyclic peroxide structure, it was also possible to assign all carbon resonances of the intermediates $\mathbf{1 b}$ and $\mathbf{2 b}$, based on HSQC and HMBC NMR data. In 1b, the magnetic equivalence of the four oxygen-bearing carbons in dianion 1a is evidently cancelled, now producing separate resonances for quinone carbons (two equivalent nuclei) and hemiketal-type carbons (two

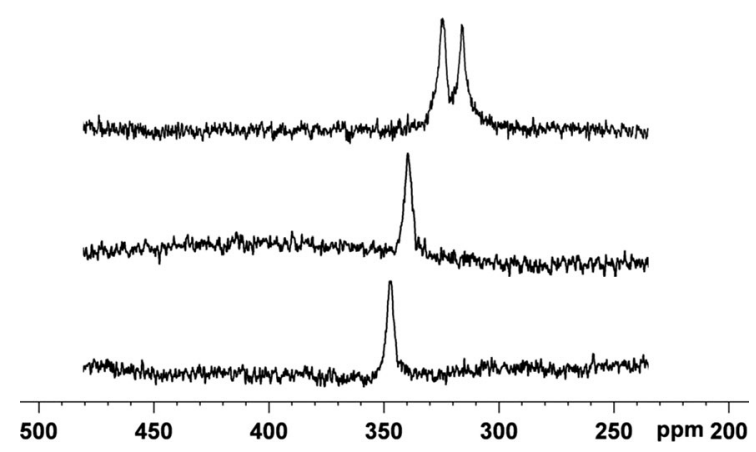

Fig. $2{ }^{17} \mathrm{O}$ NMR spectra of the symmetric cyclic peroxides $\mathbf{1 b}$ (lower trace) and $\mathbf{2 b}$ (middle trace) and the non-symmetric cyclic peroxide $\mathbf{3 b}$ (upper trace) equivalent nuclei). The protons at the methylene carbons (also two equivalent $\mathrm{C}$ ) are acidic (methyleneactive) and undergo $\mathrm{H}-\mathrm{D}$ exchange. The nature of the hemiketal-type carbons in $\mathbf{1 b}$-i.e. the "former" quinone carbons to which $\mathrm{H}_{2} \mathrm{O}_{2}$ added in a symmetric way upon peroxide formation-had been hard to assign without the input from ${ }^{17} \mathrm{O}$ NMR, because the nature of the two $\mathrm{O}$-substituents at this carbon could not be concluded just from the ${ }^{13} \mathrm{C}$ chemical shift, since hydroperoxides $\mathrm{OOH}, \mathrm{OH}$ or $\mathrm{OR}$, resulting in different forms of masked keto groups (Rosenau et al. 2005), would appear in the same shift region. Intermediate $\mathbf{2 b}$ loses the central symmetry that $\mathbf{2 a}$ has, and resumes a benzoquinoid structure, i.e. an (aromatic) hydroquinone structure anellated to a quinoid motif that carries the cyclic peroxide. Also in this compound the resonances of the hemiketal-type carbons were assigned. The proton resonances become distinguishable again (because they were in 2 ) into aromatic and quinoid ones when going from $\mathbf{2 a}$ to peroxide $\mathbf{2 b}$ (see Scheme 2). The NMR data $\left({ }^{1} \mathrm{H},{ }^{13} \mathrm{C}\right.$ and $\left.{ }^{17} \mathrm{O}\right)$ of the two chromophores, their dianions and cyclic peroxides is summarized in Tables 1 (DHBQ) and 2 (DHNQ).

An additional proof of the structure of intermediates $\mathbf{1 b}$ and $\mathbf{2 b}$ was provided by compounds 2,5dihydroxy-3-methyl-1,4-benzoquinone (3) and 5,8dihydroxy-2-methyl-1,4-naphthoquinone (4), methyl derivatives of DHBQ (1) and DHNQ (2), respectively. If subject to a reaction with alkaline peroxide, cyclic peroxides should be formed in analogy to $\mathbf{1}$ or $\mathbf{2}$, but the peroxides would not be symmetric: the methyl substituent breaks symmetry, and the two peroxide oxygens would become magnetically inequivalent. ${ }^{17} \mathrm{O}$ NMR exactly confirmed this expectation, and proved the occurrence of a cyclic peroxide intermediate $\mathbf{3 b}$ with ${ }^{17} \mathrm{O}$ resonances at 331 and $319 \mathrm{ppm}$, and a naphtha-counterpart $\mathbf{4 b}$ with ${ }^{17} \mathrm{O}$ resonances at 362 and 329 ppm (Scheme 3 and Fig. 2). Assignment of the two resonances to the two possible oxygens (Scheme 3) was based on computations on the DFT(M06-2X)/6-311+G(d,p) level.

After a reaction time of $30 \mathrm{~min}$, no intermediates were detected that were long-lived enough to allow characterization by ${ }^{17} \mathrm{O}$ NMR. Only the final degradation products were monitored, with prominent carbonate (190 ppm), acetate (274 ppm) and malonate (262 ppm) resonances ( $\mathrm{pH}$ 10). Upon acidification with $2 \mathrm{M} \mathrm{HCl}$, the carbonate signal disappeared-by release of gaseous $\mathrm{CO}_{2}$ - and the other carboxylate 
Table 1 NMR data of DHBQ (1), its dianion (1a) and the derived cyclic peroxide (1b)

\begin{tabular}{|c|c|c|c|}
\hline & $\begin{array}{l}\text { DHBQ (DMSO, } \\
1 \% \text { triflic acid) }\end{array}$ & $\begin{array}{l}\text { Dianion }\left(\mathrm{D}_{2} \mathrm{O} /\right. \\
\mathrm{NaOD}, \mathrm{pH} 10)\end{array}$ & $\begin{array}{l}\text { Cyclic peroxide }\left(1 \mathrm{M}, \mathrm{D}_{2} \mathrm{O} / \mathrm{NaOD} \text {, }\right. \\
\left.\text { pH } 10,30 \% \mathrm{H}_{2} \mathrm{O}_{2}\right)\end{array}$ \\
\hline H-3/H-6 (CH) & 5.81 & 3.87 & 2.58 \\
\hline $\mathrm{H} 2 / \mathrm{H} 5(\mathrm{OH})$ & 11.55 & Exchange & Exchange \\
\hline $\mathrm{C}-1 / \mathrm{C}-4(\mathrm{C}=\mathrm{O})$ & 182.9 & 170.8 & 184.2 \\
\hline $\mathrm{C}-2 / \mathrm{C}-5(\mathrm{C}-\mathrm{O})$ & 160.3 & 170.8 & 95.4 \\
\hline C-3/C-6 (CH) & 99.2 & 95.1 & 38.9 \\
\hline $\mathrm{O}-1 / \mathrm{O}-4(\mathrm{C}=\mathrm{O})$ & 562 & 412 & n.d. \\
\hline $\mathrm{O}-2 / \mathrm{O}-5(\mathrm{C}-\mathrm{O})$ & 72 & 412 & n.d. \\
\hline $\mathrm{O}-\mathrm{O}$ bridge & - & - & 348 \\
\hline
\end{tabular}

Data in ppm

Table 2 NMR data of DHNQ (2), its dianion (2a) and the derived cyclic peroxide (2b). Data in ppm

\begin{tabular}{llll}
\hline & DHNQ & $\begin{array}{l}\text { Dianion }\left(\mathrm{D}_{2} \mathrm{O} /\right. \\
\mathrm{NaOD}, \mathrm{pH} 10)\end{array}$ & $\begin{array}{l}\text { Cyclic peroxide }\left(1 \mathrm{M}, \mathrm{D}_{2} \mathrm{O} /\right. \\
\left.\mathrm{NaOD}, \mathrm{pH} 10,30 \% \mathrm{H}_{2} \mathrm{O}_{2}\right)\end{array}$ \\
\hline $\mathrm{H}-2 / \mathrm{H}-3$ (quinoid) & 6.55 & 3.87 & 5.64 \\
$\mathrm{H}-6 / \mathrm{H}-7$ (aromatic) & 7.32 & 3.87 & 7.15 \\
$\mathrm{H}-5 / \mathrm{H}-8$ (in $\mathrm{OH})$ & 10.30 & Exchange & Exchange \\
$\mathrm{C}-1 / \mathrm{C}-4(\mathrm{C}=\mathrm{O})$ & 190.2 & 175.2 & 184.0 \\
$\mathrm{C}-2 / \mathrm{C}-3(\mathrm{C}-\mathrm{H})$ & 109.0 & 95.8 & 108.6 \\
$\mathrm{C}-5 / \mathrm{C}-8(\mathrm{C}-\mathrm{OH})$ & 143.1 & 175.2 & 146.4 \\
$\mathrm{C}-6 / \mathrm{C}-7(\mathrm{CH})$ & 128.1 & 95.8 & 129.7 \\
$\mathrm{C}-4 \mathrm{a} / \mathrm{C}-8 \mathrm{a}$ & 115.9 & 103.6 & 118.9 \\
O-1/O-4 $(\mathrm{C}=\mathrm{O})$ & 505 & 285 & n.d. \\
O-2/O-5 $(\mathrm{C}-\mathrm{O})$ & 82 & 285 & n.d. \\
O-O bridge & - & - & 338 \\
\hline
\end{tabular}

Data in ppm

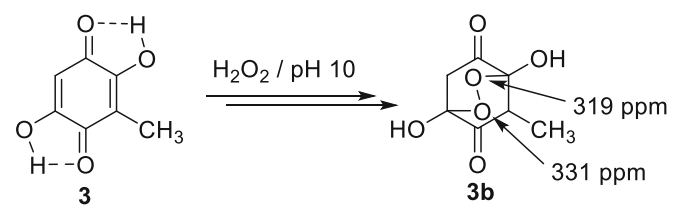

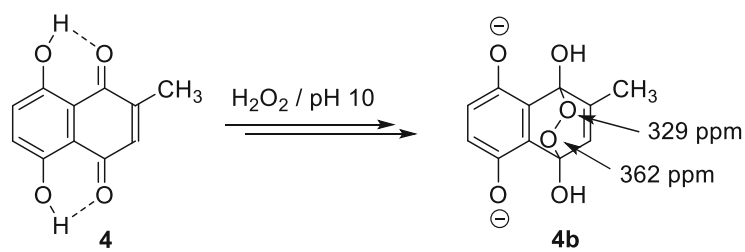

Scheme 3 Non-symmetric cyclic peroxide intermediates $\mathbf{3 b}$ and $\mathbf{4 b}$, formed from methyl derivatives of DHBQ and DHNQ signals shifted upfield, because the ${ }^{17} \mathrm{O}$ resonances of carboxylic acid groups are strongly $\mathrm{pH}$-dependent $(\Delta \delta$ up to $30 \mathrm{ppm}$ ).

\section{Conclusion}

From these ${ }^{17} \mathrm{O}$ NMR studies, the occurrence of the cyclic peroxides $\mathbf{1 b}$ and $\mathbf{2} \mathbf{b}$ as the primary intermediates in the oxidation of the cellulosic key chromophores DHBQ (1) and DHNQ (2), respectively, can be considered established, which expands our understanding of the chemistry of these compounds. Since para-quinoid structures are relatively common in the chemistry of chromophores-and also lignins - the 
result may have interesting implication on general bleaching chemistry, and lignin chemistry as well. With the advance of sensitive NMR techniques and high-field NMR spectrometers, in combination with decreasing prices for ${ }^{17} \mathrm{O}$-labeled chemicals, ${ }^{17} \mathrm{O}$ NMR spectroscopy can be reasonably expected to become more frequently used and better recognized as a quite helpful tool in mechanistic studies.

\section{Experimental section}

Commercial chemicals were of the highest grade available and were used without further purification. Reagent-grade solvents were used for all extractions and workup procedures. Distilled water was used for all aqueous solutions. Isotopically labelled ${ }^{17} \mathrm{O}$ compounds were obtained from Sigma-Aldrich (Schnelldorf, Austria) and Cambridge Isotope Laboratories, Inc. (Tokyo, Japan).

For NMR analysis, Bruker Avance II 400 (600) instruments $\left({ }^{1} \mathrm{H}\right.$ resonance at $400.13(600.19) \mathrm{MHz}$, ${ }^{13} \mathrm{C}$ resonance at $100.61(150.42) \mathrm{MHz},{ }^{17} \mathrm{O}$ resonance at $54.25(81.36) \mathrm{MHz}$ with a $5 \mathrm{~mm}$ broadband probe head (BBFO) equipped with z-gradient with standard Bruker pulse programs and temperature unit were used. Data were collected with $32 \mathrm{k}$ data points and apodized with a Gaussian window function (GB = 0.3) prior to Fourier transformation. Acquisition times of $0.5 \mathrm{~s}$ to $2.5 \mathrm{~s}$ and a $0.1 \mathrm{~s}$ relaxation delay were used for ${ }^{17} \mathrm{O}$. Bruker TopSpin 3.5 (3.0) was used for the acquisition and processing of the NMR data.

${ }^{1} \mathrm{H}$ and ${ }^{13} \mathrm{C}$ spectra were recorded in $\mathrm{D}_{2} \mathrm{O}$ or $\mathrm{D}_{2} \mathrm{O} /$ $\mathrm{NaOD}$ (pH 10) at concentrations of approx. $20 \mathrm{mg} / \mathrm{ml}$ at room temperature. ${ }^{17} \mathrm{O} \mathrm{NMR}$ experiments of the chromophores and their dianions were recorded as concentrated solutions (ca. $1 \mathrm{M}$ ) at room temperature. Spectra of the cyclic peroxides were taken in concentrated solutions $\left(\mathrm{D}_{2} \mathrm{O} / \mathrm{NaOD}\right)$ after addition of $30 \%$ $\mathrm{H}_{2} \mathrm{O}_{2}$ (molar ratio chromophore $/ \mathrm{H}_{2} \mathrm{O}_{2}$ of $1: 3$ ) at $0{ }^{\circ} \mathrm{C}$.

Computations were carried out by geometry optimization at the DFT(M06-2X)/6-31+G(d,p) level followed by computation of the NMR shielding with the lager basis functions of $6-311+\mathrm{G}(\mathrm{d}, \mathrm{p})$, using the Gaussian program package.

Acknowledgments Open access funding provided by University of Natural Resources and Life Sciences Vienna
(BOKU). The authors would like to thank the Austrian Research Promotion Society (FFG, project "Chromophores II") for financial support.

Open Access This article is distributed under the terms of the Creative Commons Attribution 4.0 International License (http:// creativecommons.org/licenses/by/4.0/), which permits unrestricted use, distribution, and reproduction in any medium, provided you give appropriate credit to the original author(s) and the source, provide a link to the Creative Commons license, and indicate if changes were made.

\section{References}

Becker ED (1999) For the topic of symmetry and NMR spectroscopy see for instance. In: High resolution NMR. Theory and chemical applications, 3rd edn. Academic Press, London

Berger S, Braun S, Kalinowski H-O (eds) (1997) NMR spectroscopy of the non-metallic elements. Chichester, Wiley, pp 319-397

Boykin DW (ed) (1990) ${ }^{17}$ O NMR spectroscopy in organic chemistry. CRC Press, Boca Raton

Chandrasekaran S, Wilson WD, Boykin DW (1984) ${ }^{17}$ O NMR studies on polycyclic quinones, hydroxyquinones and related cyclic ketones: models for anthracycline intercalators. Org Magn Reson 22:757

Gerothanassis IP (2010a) Oxygen-17 NMR spectroscopy: basic principles and applications (part I). Prog Nucl Magn Reson Spectrosc 56:95-197

Gerothanassis IP (2010b) Oxygen-17 NMR spectroscopy: basic principles and applications (part II). Prog Nucl Magn Reson Spectrosc 57:1-110

Hosoya T, Rosenau T (2013a) Degradation of 2,5-dihydroxy$[1,4]$-benzoquinone by hydrogen peroxide under alkaline conditions resembling pulp bleaching: a combined kinetic and theoretical study. J Org Chem 78(22):11194-11203

Hosoya T, Rosenau T (2013b) Degradation of 2,5-dihydroxy$[1,4]$-benzoquinone by hydrogen peroxide: a combined kinetic and theoretical study. J Org Chem 78(7):3176-3182

Klemperer WG (1978) ${ }^{17} \mathrm{O}$ NMR spectroscopy as structural probe. Angew Chem Int Ed Engl 17(4):246-254

Korntner P, Hosoya T, Dietz T, Eibinger K, Reiter H, Spitzbart M, Röder T, Borgards A, Kreiner W, Mahler AK, Winter H, French AD, Henniges U, Potthast A, Rosenau T (2015) Chromophores in lignin-free cellulosic materials belong to three compound classes. Chromophores in cellulosics, XII. Cellulose 22(2):1053-1062

Rosenau T, Potthast A, Kosma P, Saariaho A-M, Vuorinen T, Sixta $H$ (2005) On the nature of carbonyl groups in cellulosic pulps. Cellulose 12(1):43-50

Zwirchmayr NS, Hosoya T, Henniges U, Gille L, Bacher M, Furtmüller P, Rosenau T (2017) Degradation of the cellulosic key chromophore 5,8-dihydroxy-[1,4]-naphthoquinone by hydrogen peroxide under alkaline conditions. J Org Chem 82(21):11558-11565 